\title{
Etiquetas discursivas y categorización de expresiones lingüísticas precedentes.
}

\section{Discursive labels and categorization of preceding linguistic expressions.}

DOI: 10.32870/sincronia.axxv.n80.22b21

\author{
Marcela Bonnet \\ Universidad Nacional de Río Cuarto. (ARGENTINA).
}

CE: marcelabonnet@hotmail.com

Daniela S. González

Universidad Nacional de Cuyo. (ARGENTINA).

CE: gonzalezdanielasoledad@yahoo.com.ar / ID ORCID: 0000-0003-2437-531X

\section{Esta obra está bajo una Licencia Creative Commons Atribución-NoComercial 4.0 Internacional}

Recibido: 08/03/2021

Revisado: 30/04/2021

Aprobado: 14/05/2021

\section{RESUMEN}

En este artículo, estudiamos los procesos de categorización de expresiones lingüísticas precedentes a través de procedimientos de etiquetaje discursivo anafóricos. Estos procedimientos anafóricos pueden ser entendidos como un tipo de reformulación parafrástica que los estudiantes utilizan al etiquetar información proveniente de diversas fuentes. El análisis se basa en una descripción del uso de estos mecanismos a partir de la identificación manual de 70 etiquetas en un corpus de 15 textos monográficos y ensayísticos que produjeron estudiantes de diversas disciplinas del profesorado de Lengua y Literatura de la Universidad de Río Cuarto en el año 2015 como instancia de acreditación de los espacios 
curriculares. El uso de este recurso deja entrever las cargas metadiscursivas, epistémicas y axiológicas que se manifiestan al reformular e interpretar discursos ajenos. Los resultados obtenidos muestran que en la reelaboración y apropiación conceptual de la información se reformula el conocimiento, al tiempo que se transforma y construye.

Palabras Clave: Escritura Académica. Etiquetas Discursivas. Anáfora. Reformulación. Categorización.

\section{ABSTRACT}

In this paper, we study the processes of categorization of preceding voices trhow discursive labeling procedures. This anaphoric procedures can be understood as a type of paraphrasic reformulation used by the students by labeling information from several sources. The analysis is based on a description of the use of these mechanisms beginning with the manual identification of 70 labels in a corpus of 15 texts with monographies and essays features, written the students of different disciplines of the Language and Literature carrers of Río Cuarto University in 2015. The texts were produced as a proof of accreditation of curricular spaces. The use of these resource allows us to entrust the metadiscoursive, epistemic and axiologic burdens that they support when they reformulate and interprete other people's discourses. Results show that in the re-elaboration and conceptual appropiation of the knowledge, it is, at the same time, reformulated and constructed.

Keywords: Academic Writing. Discursive labels. Anaphore. Reformulation. Categorization. 


\section{Las etiquetas discursivas: dialogismo y reformulación}

Numerosos estudios postulan que la reformulación constituye una habilidad prioritaria para que los estudiantes afronten el desafío de escribir en diversos contextos disciplinares a lo largo de su vida universitaria (Silvestri, 1998; Carlino, 2005; Arnoux y Pereira, 2002; Arnoux, Silvestri y Nogueira, 2002; Novo, 2007; Arnoux 2009; Vazquez, 2016; Carlino, 2013; Padilla 2013, Bazerman, 2013; Navarro, 2017).

En el caso de la reformulación que nos interesa, la anafórica, se retoma un fragmento textual precedente o texto fuente (TF) para decirlo de otro modo, de lo que resulta un texto meta o etiqueta discursiva (ED). La ED resultante evidencia una selección de la información del TF y permite vislumbrar la carga ideológica y axiológica del enunciador. Al volver a decir lo dicho no solo se reproduce el conocimiento, sino que también hay una apropiación y transformación (Scardamalia y Bereiter, 1992; Silvesri, 1998; Alvarado y Cortés, 2001). En el diálogo con lo construido en la comunidad discursiva, el hablante puede hacer apreciaciones sobre su carácter de verdad, su estatuto epistemológico, su intencionalidad y sus posibles efectos.

\section{Acerca de nuestro objeto de estudio: consideraciones previas}

\section{Estado de la cuestión}

Si bien las EEDD son estudiadas prioritariamente como un mecanismo cohesivo, existen diferentes perspectivas de abordaje de la temática. Por ello, no resulta extraño que la bibliografía denomine de maneras diversas a este tipo peculiar de anáfora: "de entidades abstractas" (Asher, 1993), "difusa" (Fernández, 1987), "por nominalización" (Apothéloz, 1995), “recapitulativa o resumitiva” (Vivero, 1997), "conceptual" (Borreguero, 2006; Llamas, 2010). Aquí hablamos de "etiqueta discursiva" siguiendo a Francis (1994) y López Samaniego (2011), en tanto privilegiamos como rasgo central la reelaboración conceptual del segmento anterior. 
Respecto de las investigaciones recientes sobre el tema, hay trabajos constrastivos que analizan la forma en que se interpretan las EEDD en diversas lenguas y/o países (Andújar, 2000; Abad, 2015; González, 2008, 2010; Peña, 2006; Zamponi, 2003) y los que tratan el fenómeno como un tipo de metáfora conceptual (Llamas, 2010). En esta línea, un aporte indispensable es el de López Samaniego (2011, 2013a, 2013b, 2018), que caracteriza los procedimientos de etiquetaje y los diferencia de otras operaciones.

La mayoría de los estudios se ocupa de textos del género artículo de divulgación científica y artículo de periódico o revista. El análisis de mecanismos de etiquetaje no es frecuente en corpus de textos académicos, si bien hay algunas investigaciones en el ámbito de la educación general básica (Borzone, 2005), en el nivel superior (Mayela y Manrique, 2004; Torres y Boces, 2012) y sobre aspectos técnicos de la escritura científico-académica (Ávila, 2016). No hallamos estudios sobre el uso de mecanismos de etiquetaje como un tipo reformulador específico ni que analicen su tarea en la apropiación de conceptos. Nuestro objetivo es describir cómo los estudiantes se apropian de voces precedentes a través del uso de EEDD y cuál es el posicionamiento epistemológico, ideológico y axiológico que dejan entrever.

\section{Etiquetas discursivas: delimitación y caracterización del fenómeno}

Nuestro objeto de estudio, las EEDD anafóricas, se inscribe en los mecanismos de cohesión anafóricos indirectos o libres. Se alejan de las formas canónicas en tanto no pueden explicarse por la relación semántica correferencial que guardan con un antecedente, ni por una relación morfosintáctica de concordancia con dicho elemento. El antecedente dispara la interpretación anafórica con procesos inferenciales ${ }^{1}$.

\footnotetext{
${ }^{1}$ Un exponente de este tipo de anáforas son las asociativas en las que existe un vínculo semántico-estereotípico entre el elemento anafórico y su antecedente. Un ejemplo como "Entramos a la casa. Las puertas estaban abiertas" constituye un tipo anafórico asociativo puesto que el sintagma "las puertas" designa una entidad que debe inferirse a partir de un sintagma no correferencial presente en la oración anterior: "la casa". Así "las puertas" a las que se alude en el ejemplo
} 
En términos generales, podemos mencionar al menos tres rasgos que posibilitan definir al fenómeno de las EEDD anafóricas: (a) su capacidad para condensar información, (b) el carácter muchas veces abstracto del referente y (c) el carácter difuso del antecedente (López, 2011, pp. 293362). La capacidad de condensar información proposicional en un sintagma nominal (SN) se evidencia el siguiente ejemplo de nuestro corpus:

(1) La literatura se pone al servicio de los hechos que no pueden olvidarse y ayuda a revelar esos datos que resultan "escondidos" en el pasado, esta tarea es llevada a cabo de distintas maneras ${ }^{2}$.

Hemos colocado en cursiva el TF y en negrita la etiqueta discursiva anafórica. De ahora en adelante, seguimos este método de marcación. En (1), se aprecia que "esta tarea" categoriza una información precedente, la condensa y realiza un ajuste conceptual del antecedente nombrándolo de otro modo. Es un caso de "anáfora de dicto o cognitiva" en tanto reformula las acciones de la literatura "ponerse al servicio de" y "ayudar a revelar", como una "tarea".

Respecto del carácter abstracto del referente, está ligado a la pérdida de tiempo, modo, aspecto y persona, lo que produce una reelaboración conceptual del antecedente: la "reificación", o conversión de un abstracto en una "cosa" u "objeto unitario conceptualmente delimitado" (Langacker, 1987; 2008, p. 107). Observemos el ejemplo (2):

son "las puertas que pertenecen a esa casa", asociación posible a la que se llega mediante una inferencia ("las casas tienen puertas"). Dicha inferencia se basa en una relación meronímica entre la parte (puertas) y el todo (casa).Otros autores (Barrendonner, 1986; Apothéloz, 1995; Cornish, 1990, entre otros) consideran que la relación asociativa puede efectuarse a partir de operaciones inferenciales que se establecen en función de los datos que brinda el discurso y del conocimiento de mundo, sin que la asociación funcione necesariamente como una relación semántico-estereotípica. La dependencia interpretativa de una anáfora no solo se vincula con el contexto verbal explícito, sino también con la memoria discursiva.

${ }^{2}$ Los ejemplos que no presenten referencia a sus fuentes son tomados del corpus. Esos datos no se colocan porque se desea resguardar las identidades de sus enunciadores. Aquellos ejemplos en los que se enuncien los autores son tomados de la bibliografía. 
(2) Hace apenas unos días los medios trataron en su agenda la vuelta de la democracia, de la cual se cumplieron treinta y un años el pasado 30 de octubre. Para algunos tal acontecimiento representa una importante celebración y para otros, quizás un poco desmemoriados, ajenos o incluso desconocedores de la historia argentina reciente, solo una fecha, un año más de vida en democracia. En este marco de heterogeneidad considero que caben preguntas [...].

En (2), la ED "este marco de heterogeneidad" se evidencia la pérdida tanto de los agentes como de los predicados verbales que componen el segmento antecedente. Se transforma lo dicho con estructuras verbales en el SN "este marco de heterogeneidad". Se nombra una entidad unitaria a la que, a su vez, pueden sumársele atributos. Cabe resaltar que difícilmente encontraremos como EEDD sustantivos comunes concretos como puerta (Llamas, 2010). Esto se debe a que por lo general las EEDD categorizan entidades de un orden ${ }^{3}$ más alto que el de los objetos físicos. Por lo general, entidades de segundo y tercer orden, i. e., de alto grado de abstracción, que suelen ser compatibles con las entidades del conocimiento científico.

El tercer rasgo de las EEDD es el carácter difuso del antecedente. Los antecedentes recategorizados difieren en complejidad y extensión. La posibilidad de reelaborar el contenido y añadir información explica que, en muchas ocasiones, el antecedente textual resulte difícil de ser delimitado; suele ser "difuso" e incluso "impreciso". Hay casos en que el elemento retomado es un verdadero paquete informativo como en (3):

(3) Entre otros relatos se puede destacar Diario de un clandestino de Miguel Bonasso, escrito, no para hacer memoria sino que los comienzos de este diario cumplieron el propósito de archivo personal del escritor. Por un pedido de publicación, Bonasso decide dar a conocer sus agendas y

\footnotetext{
${ }^{3}$ Lyons (1977) propone una clasificación ontológica de las entidades, que prototípicamoente expresamos mediante expresiones nominales. Las de primer orden, que son concretas (personas, animales, cosas); las de segundo orden (se desarrollan en un tiempo y espacio: estados, eventos, procesos, actividades), y las de tercer orden, que son las de mayor grado de abstracción; son conceptos y proposiciones que se presentan por fuera del espacio y el tiempo (v. gr., esperanza, creencia y juicio).
} 
cuadernos. Desde entonces se ha convertido en algo más que un simple diario de archivo secreto de un militante de los años '70. Por su relato atrapante y sus historias reales, comenzó a tomarse como testimonio de un periodista que, en época de la represión, por sus ideologías encontradas con el gobierno militar, tuvo que vivir en la clandestinidad junto con su familia. Además debió exiliarse a México para conservar su vida. En el diario está expresa una crónica integra, contada por su escritor y protagonista al mismo tiempo, llena de situaciones complejas, relatos heroicos de sus compañeros, el crecimiento de sus hijos en una vida oculta y episodios atrapantes por su carácter real. Si bien la información es tomada de un diario personal, Bonasso debió adaptar su contenido para poder publicarlo. Agregó detalles y suprimió otros. Así logra captar la atención del lector. Reunió su experiencia de vida, con situaciones inesperadas. La lectura de este tipo de obras literarias (referidas a la represión como recurso para construir memoria) colaboran con la construcción del pasado reciente.

Puede considerarse que "este tipo de obras literarias" constituye una ED que alude o bien a la obra Diario de un Clandestino, o bien -y esta nos parece la interpretación más plausible- al conjunto de características a partir de las cuales el enunciador describe a la obra. El antecedente al que alude la ED se presenta difuso. Además, también se lleva a cabo una suerte de reclasificación hiperonímica de este paquete informativo al incluir a la mencionada obra en el conjunto amplio de "obras literarias referidas a la represión como recurso para construir memoria" sobre el pasado reciente en Argentina.

A los tres rasgos con que definimos a las EEDD, parece interesante sumar el análisis de la modalización y las consideraciones metadiscursivas, que ponen de manifiesto las EEDD, pues hemos apreciado que estos recursos son de utilidad para explicitar el modo en que se produce la reelaboración y apropiación conceptual de voces correspondientes a autores legitimados por la comunidad discursiva. En (4), por ejemplo, observamos una clasificación del TF, que presenta el tema de la subjetividad de Martí como insuficientemente estudiado, de modo tal que se lo ubica como el punto de partida de un artículo de investigación: 
(4) Hasta donde se ha revisado, las formas de expresión de la subjetividad martiana en sus trabajos periodísticos no han sido suficientemente estudiadas, a diferencia de otros aspectos compositivos de su estilo. A partir de esta motivación inicial, en este artículo se describen las formas de expresión de la subjetividad martiana mediante la modalización discursiva de sus juicios, lo cual constituye una de las aristas de la manifestación textual de los pareceres individuales (Pérez, 2016, pp. 189-190).

En (4), con la ED "esta motivación inicial”, la enunciadora posiciona el TF como la motivación que origina su indagación. Debido a que ese fragmento señala que hay aspectos sobre la subjetividad en las obras de Martí sin investigar lo suficiente, se trata de una laguna de investigación y su retome anafórico insiste en clarificar que el artículo es el que va a ocupar ese nicho. Así, se lleva a cabo un posicionamiento epistémico del TF. Se lo retoma en función de su papel en la construcción del estatuto científico de la investigación. Esta operación es una forma de modalización. Delimitemos este concepto con las palabras de la misma autora del ejemplo:

[Maria Grau Tarruell] define la modalización como «un concepto pragmático que se refiere a las actuaciones concretas de los hablantes que producen enunciados en los que dejan trazas de su manera de pensar y de sentir, de sus actitudes». De ahí que Marcia Losada (2011) lo defina como uno de los componentes que permite relacionar el nivel semioenunciativo (discurso) con el nivel semio-cognitivo (sistema subyacente) (Pérez, 2016, p. 184).

Veamos otro ejemplo. En (5) se sitúa el TF, que corresponde a la enunciación del objeto de estudio y la proyección de la continuación de la investigación, en relación con un proyecto de alcance mayor planificado para ser desarrollado en fases. En este procedimiento de etiquetaje discursivo también se ubica epistémicamente la información retomada. Se la encapsula en la idea de fase de un 
proyecto mayor. Por lo tanto, como en el ejemplo anterior, se retoma información anterior en función de su papel en la planificación de la investigación.

(5) El presente estudio sobre los componentes semántico-discursivos en el periódico conservador apunta a su lógico complemento: un análisis similar de tales componentes en la prensa de izquierda. Esta fase de nuestro proyecto sobre el español de la Guerra Fría en Chile debe conectarse con los estudios en proceso de publicación sobre las estrategias semánticas generales en ambos campos (...), para culminar con un análisis comparativo de los datos textuales de los corpus de El Diario llustrado y de EI Siglo (Latorre, Vega y Opazo, 2002, p. 70).

A continuación, un ejemplo más, en el que se retoma un fragmento extenso, en el que se afirma que no se hallaron marcadores con participios epistémicos en un corpus conversacional. La ED es "lo que sí es cierto" y, claramente, es un índice de modalidad epistémica, pues pone de manifiesto la postura del enunciador respecto de la verdad del enunciado precedente.

(6) Otro tipo formal de marcadores que encontramos en el corpus científico y no en el conversacional es el constituido por marcadores con participios epistémicos. La ausencia total de este tipo de unidades en el corpus conversacional no tiene una explicación clara, pudiendo ser, por tanto, una consecuencia de las limitaciones inherentes a cualquier estudio de corpus. De todos modos, lo que sí es cierto es que las características específicas del discurso científico determinan que el hablante necesite recurrir a ciertos participios como comprobado o demostrado, con un contenido semántico poco utilizado en la conversación (Fernández, 2009, pp. 585-586).

El último ejemplo que analizamos en esta sección tiene, además de un tinte epistémico, uno valorativo. Con la ED "Esta circunstancia" se retoma el fragmento precedente, en el que se indica que las nominalizaciones permiten generar un efecto de objetividad, que se aprovecha ampliamente en el registro científico. 
(7) Eggins y Martin (1997: 363) profundizan en esta última idea, y a todo lo dicho anteriormente, añaden otra posible ventaja, para el discurso científico, de las construcciones nominalizadas. Se trata del hecho de que este tipo de estructuras permiten a los autores establecer una distancia entre ellos y los lectores $y$, sobre todo, entre ellos y los hechos concretos tratados en el texto, dando a entender que no se implican emocionalmente en éstos. Esta circunstancia puede ser utilizada para lograr la impresión de objetividad y neutralidad típicas del lenguaje de ciencia (Fernández, 2009, p. 589).

Podría haberse hecho referencia a esto de diferentes maneras, como estrategia discursiva o uso. En cambio, se hizo uso de la expresión circunstancia, que desfocaliza la agentividad de los enunciadores académicos que utilizan las nominalizaciones. Más adelante, se habla de lo mismo y se refieren a esto como "recurso". La expresión que utilizan es "recursos como el de la nominalización" (Fernández, 2009, P. 590). Otras EEDD que suelen aparecer en con función anafórica en los textos son "este (breve/extenso/detallado) repaso", "estos datos", "esta información", "la distinción precedente", "dicha aclaración", "estos comentarios", "aquella crítica", entre muchos otros. Etas opciones pueden marcar distinciones modales epistémicas y de evidencialidad e incluso modalizaciones valorativas. También se pueden encontrar otras EEDD más claras y de mayor carga valorativa como "tal acusación" o "esta suposición".

Para delimitar la noción de modalidad epistémica que ha entrado en escena, baste con decir que se refiere a "la expresión lingüística del grado de compromiso que el hablante asume respecto a la factualidad de su enunciado" (Fernández, 2009, pp. 577-578), que puede estar asociada a la evidencialidad o manifestación de la fuente del enunciado. Además de la modalidad epistémica, tradicionalmente se diferencian la modalidad apreciativa, que hemos mencionado arriba, y la modalidad deóntica, las cuales son delimitadas por Pérez García (2016, p. 185-186). La autora señala que la modalización valorativa se halla en las expresiones de juicios de valor sobre lo dicho, las cuales se llevan a cabo con recursos como los subjetivemas, la cuantificación, ciertos adverbios y algunas "figuras". Por último, la modalidad deóntica es la que se dirige al receptor y consiste en la 
expresión de la necesidad u obligación de actuar de una determinada forma. Hace uso de recursos como el modo verbal imperativo, verbos y perífrasis verbales modales, y otros recursos.

\section{Las etiquetas discursivas como caso de reformulación parafrástica}

\section{Reformulación no parafrástica y reformulación parafrástica}

La oposición entre "distinta" y "equivalente" es lo que fundamentalmente distingue a la reformulación no parafrástica de la parafrástica (Abad, 2015, p. 132). La primera implica un cambio de perspectiva enunciativa, y aparece señalada por marcadores como "de hecho" y "en suma". En cambio, en la segunda, se vuelve sobre la formulación original con el fin de clarificarla, expandirla o incluso reducirla, pero siempre estableciendo una relación de equivalencia entre ambos términos en algún nivel.

Los reformuladores parafrásticos más frecuentes son explicativos (v. gr., "es decir", "esto es", "en otras palabras") o rectificativos (v. gr., "mejor dicho", "más bien”). También la reformulación parafrástica puede darse sin la presencia del reformulador, con la reiteración de algún aspecto de orden sintáctico o terminológico: reiteraciones léxicas, frases explicativas, verbos con función metalingüística (Penas y Serna, 2011, p. 31). Si bien la reformulación parafrástica suele ser definida como una sinonimia sintagmática (Penas, y Serna 2011, p. 31), no puede pensarse como relación de intercambiabilidad o decir "lo mismo de otra manera" (Silvestri, 1998) porque lo que se dice de otra forma nunca es "lo mismo". La equivalencia semántica es la relación que atribuye a los enunciados vinculados en la paráfrasis una base sémica común y una serie de rasgos diferenciales condicionados por la situación y el contexto sintagmático.

Consideramos que las EEDD pueden hallarse dentro de este último grupo. Es decir, constituyen un tipo de reformulación parafrástica que no presenta un marcador de reformulación explícito. En los casos trabajados, el enunciador presenta la ED inmediatamente después de citas -ya sean directas o indirectas-, lo que le otorga a este tipo especial de reformulación un carácter de contestación a voces 
precedentes. En general, las EEDD suelen estar conformadas por sintagmas nominales constituidos por pronombres determinativos o demostrativas, más un sustantivo que en ocasiones es modificado por algún tipo de adjetivo.

Nuestro análisis explora los vínculos entre el primer segmento discursivo (TF) y la ED que reformula tal segmento. Como ya mencionamos, nos ocuparemos de describir cuáles son los rasgos semánticos que permanecen estables y cuáles son las modificaciones, restituciones, o desplazamientos que se operan.

\section{Materiales y Métodos}

En este trabajo, describimos y clasificamos el funcionamiento de 70 casos de EEDD identificados manualmente en un corpus acotado de 15 textos de tipo monográfico y ensayístico correspondientes a estudiantes del Profesorado en Lengua y Literatura de la Universidad Nacional de Río Cuarto, durante los dos últimos años de la carrera. Realizamos una valoración fundamentalmente cualitativa en la que procuramos caracterizar la forma en la que los enunciadores reformulan parafrásticamente voces precedentes a través de procedimientos de etiquetaje discursivo en textos correspondientes a las asignaturas Literatura Argentina I (3. año) y Literatura Hispanoamericana I y II (4.ำ año). Esta es una aproximación sincrónica en la que recolectamos trabajos producidos durante el ciclo lectivo 2015. Esta elección se fundamentó en nuestro interés por conocer cómo los estudiantes despliegan estas formas de reformulación anafórica en géneros textuales solicitados en instancias de evaluación final, en las que deben apropiarse de las teorías sobre crítica literaria y en función de esta apropiación realizar una lectura personal de las obras literarias. 


\section{Resultados y Discusiones}

Los resultados hallados evidencian que los procedimientos de EEDD que los enunciadores despliegan al reformular segmentos precedentes correspondientes a citas directas e indirectas cumplen funciones diversas y graduales que van desde la reiteración de algún ítem léxico a la creación de una entidad absolutamente inédita que construye el enunciador al interpretar el contenido de la voz precedente. La tabla 1, que se presenta a continuación, muestra la clasificación de las diversos tipos y funciones que cumplen los procedimientos de EEDD hallados en el corpus.

Gráfico 1 Tipos y funciones de las EEDD registradas

\begin{tabular}{|c|c|c|}
\hline $\begin{array}{l}\text { Funcione } \\
\text { s }\end{array}$ & $\begin{array}{l}\text { Formalizació } \\
\text { n de un acto } \\
\text { de habla }\end{array}$ & $\begin{array}{l}\text { Interpretación y valoración del segmento precedente. La ED } \\
\text { muestra. } \\
\text { La restitución o el desplazamiento de elementos provenientes del } \\
\text { segmento reformulado. } \\
\text { La generación de una entidad inédita (recategorización). } \\
\text { La modalización (manifestación de la actitud del hablante). }\end{array}$ \\
\hline
\end{tabular}

\section{Anáforas de RE}

Como se ha adelantado, existen EEDD cuya función es la de reformular contenidos proposicionales de segmentos textuales previos a través de una categorización que suele ser metalingüística, es decir, que implica categorizar el segmento precedente como un acto de lenguaje. Este tipo de EEDD corresponde a las denominadas anáforas de RE. Así puede observarse en los ejemplos (8) y (9):

(8) "si exterminamos al gaucho también exterminamos con él nuestra riqueza y nuestro futuro desarrollo económico. Si cuidamos al gaucho nos enriquecemos" (Feinmann, 1996: 293). Esta postura es contraria a la ideología y proyecto de nación que asumía Sarmiento. 
(9) En el plano epistémico, Cortés (2013) ignora, desestima al otro y a las posibilidades de su cultura [...]. Menciona indistintamente a la ciudad de Tenochtitlán como "temixtitan" o "tenuxtitan". Y considera propio y oportuno enviar a los nativos de Guasincango "un mandamiento firmado de mi nombre y de un escribano con relación larga de la real persona de vuestra sacra majestad" [...]. Estas decisiones no son más que muestras de desconsideración de la identidad y de la cultura oral del otro.

Como puede verse en estos ejemplos, las voces de los segmentos precedentes son categorizadas como "esta postura" y "estas decisiones". Estos tipos anafóricos de RE reformulan un acto de lenguaje como pregunta, orden, deseo, recomendación, decisión, ejemplificación, etc. Y, si bien cumplen con la función de categorizar una voz precedente -lo que de por sí evidenciaría algún tipo de interpretación- la carga valorativa y axiológica es menor a las de otras formas de etiquetaje (Gonzalez, 2008). O, más precisamente, su carga valorativa, que está muy unida a la caraterización metadiscursiva que llevan a cabo, es más bien epistémica y no apreciativa.

En el gráfico 2, que se presenta a continuación, enumeramos cada una de las EEDD identificadas en el corpus que cumplen con esta función de RE. Cabe destacar que de las 70 EEDD identificadas, 32 corresponden a estos casos, lo que representa aproximadamente un 45,71\% del total, lo que muestra una prevalencia de estos usos por sobre los otros tipos. 


\section{Gráfico 2}

\section{Sistematización de EEDD con función de anáforas DE RE}

\begin{tabular}{|c|c|c|}
\hline $\begin{array}{ll}\text { - } & \text { este fragmento } \\
\text { - } & \text { esta concepción } \\
\text { - } & \text { estas categorías } \\
\text { - } & \text { dicho argumento } \\
\text { - } & \text { esta idea } \\
\text { - } & \text { este diálogo } \\
\text { - } & \text { estas palabras } \\
\text { - } & \text { esta concepción } \\
\text { - } & \text { esta razón } \\
\text { - } & \text { esta preguntas } \\
\end{array}$ & $\begin{array}{l}\text { - } \text { esta concepción } \\
\text { - } \text { este fragmento } \\
\text { - } \text { esta descripción } \\
\text { - } \text { este fragmento } \\
\text { - } \text { estas palabras } \\
\text { - } \quad \text { esta postura } \\
\text { - } \quad \text { esta tesis } \\
\text { - } \quad \text { esta postura } \\
\text { - últimas palabras } \\
\text { - } \quad \text { esa línea } \\
\text { - } \text { puntos de relación }\end{array}$ & $\begin{array}{ll}\text { - } & \text { estos ejes } \\
\text { - } & \text { esas decisiones } \\
\text { - } & \text { este ejemplo } \\
\text { - } & \text { esta frase } \\
\text { - } & \text { ambas versiones } \\
\text { - } & \text { estos testimonios } \\
\text { - } & \text { este discurso } \\
\text { - } & \text { este último fragmento } \\
\text { - } & \text { estas últimas palabras } \\
\text { - } & \text { estas canciones }\end{array}$ \\
\hline
\end{tabular}

\section{Anáforas de dicto o cognitivas}

Mientras que en las EEDD que cumplen funciones anafóricas de RE se enuncia el acto de lenguaje que lleva a cabo el enunciador, en las otras -anáfora de Dicto o Cognitivas- se interpreta y suele evaluarse el contenido proposicional precedente. Advertimos que en estas etiquetas los enunciadores muestran distintos grados de apropiación de la información del TF que va desde la restitución y/o desplazamiento de algún ítem lexical del segmento precedente a la generación de una entidad inédita.

\section{Anáforas de dicto o cognitivas (Grupo A): la cuestión de la anáfora acumulativa}

En el gráfico 3 sistematizamos todas las recurrencias correspondientes a las EEDD de dicto (grupo A) que muestran restitución y/o desplazamiento de algún ítem lexical. Hallamos 8 casos, lo que 
representa un $11,42 \%$ sobre el total de EEDD identificadas. Es decir, evidencian en este caso la menor prevalencia de uso.

\section{Gráfico 3}

Sistematización de EEDD con función Anáforas de dicto (grupo A). Restitución/ desplazamiento de ítems léxicos

- esta construcción

- la vida feliz

- ese infierno

- esos modelos utilitarios

- esta originalidad

- estas identidades plurales

- este desplazamiento

- esta diferencia de cosmovisiones

Al analizar el funcionamiento de algunos de estos casos podemos observar que, como sucede en (10), el enunciador restituye en la etiqueta un ítem lexical procedente del segmento reformulado "construcción" a partir del cual se categoriza el antecedente como "esta construcción".

(8) Así lo sostiene Hozven (en Moyano, 2009): "La identidad nacional se realiza de un modo performativo y no meramente constatativo de fuentes o documentos preexistentes. Emerge como un efecto o construcción de lo que se va pensando y escribiendo al hacerla y de lo que no se tenía idea antes de comenzarla. En esta construcción de la nacionalidad entra en juego el binomio civilización barbarie. 
Sintácticamente en (10) la ED está conformada por un SN conformado por un pronombre demostrativo más un sustantivo, lo que puede formularse de la siguiente manera: (SN)= PD + sust. Es importante destacar que observamos un desplazamiento del ítem "construcción" en tanto en el segmento precedente forma parte del predicado verbal y en la etiqueta aparece en posición temática. En este caso, la función que cumple la etiqueta no es estrictamente la de interpretación del antecedente, sino más bien la de restitución del ítem lexical que acumula la información de todo el conjunto proposicional mencionado anteriormente. La ED cumple una función anafórica acumulativa (Evans, 1980, p. 340). Es decir, la ED "esta construcción" no alude correferencialmente al ítem lexical "construcción" que figura en el segmento antecedente, sino que su alcance trasciende a este único antecedente textual directo para comprometer todo el conjunto proposicional. Esta ED refiere a la construcción de la identidad nacional que se "realiza o construye de un modo performativo...".

Una de las principales implicancias del enfoque acumulativo es que pone en cuestión "la relación de estricta correferencia que presidía los enfoques tradicionales, lo que constituye uno de los puntos de partida de la concepción de anáfora denominada acumulativa" (López, 2011, p. 64). Autores como Brown y Yule (1983) centran su atención en textos que comprenden predicados de transformación de estado -que se hallan en textos narrativos y en recetas de cocina- y critican la correferencialidad que defienden las corrientes sustitutivas para explicar las relaciones que se establecen entre una expresión anafórica y un antecedente (López, 2011, p. 65). Del mismo modo en (11), la ED “estas identidades plurales" condensa acumulativamente las características que se encuentran en el segmento antecedente (superpuestas, diversas y contradictorias):

(8) Como sostiene Cornejo Polar (1999), en América Latina conviven -en un mismo presenteidentidades plurales superpuestas, diversas y contradictorias que constituyen una heterogeneidad conflictiva. Estas identidades plurales requieren la construcción epistemológica de un nuevo 
objeto de estudio.

Este tipo de interpretación enfatiza la necesidad de tener en cuenta toda la cláusula en la que aparece el antecedente "identidades plurales" para interpretar la expresión anafórica. En las expresiones anafóricas van incorporándose progresivamente las entidades "esta construcción" y "estas identidades" y modifican sus propiedades. Sus rasgos van transformándose progresivamente a lo largo de las sucesivas cadenas anafóricas (Brown y Yule, 1983, p. 26).

\section{Anáforas de dicto o cognitivas (Grupo B): la generación de entidades inéditas}

A diferencia de lo expuesto anteriormente en (10) y (11), aquí agrupamos los procedimientos de etiquetamiento discursivo en los que una anáfora de dicto interpreta el contenido proposicional expuesto por la voz precedente, pero en este caso construyendo una entidad inédita que en algunas ocasiones conlleva fuertes implicancias axiológicas y argumentativas. Este tipo de anáforas, entonces, se utiliza con una clara función modalizadora apreciativa. 


\section{Gráfico 4}

\section{Sistematización de EEDD con función Anáforas de dicto (grupo B). Generación de entidades} inéditas

\begin{tabular}{|c|c|}
\hline $\begin{array}{ll}\text { - } & \text { los enfrentamientos entre posturas } \\
\text { - } & \text { diferentes y antagónicas } \\
\text { - } & \text { modelo del progreso } \\
\text { - } & \text { esta dicotamía } \\
\text { - } & \text { ese plan de exterminio } \\
\text { - } & \text { ese plan } \\
\text { - } & \text { la imposición del cristianismo } \\
\text { - } & \text { la imagen de este hombre } \\
\text { - } & \text { estas estrategias } \\
\text { - } & \text { este hecho } \\
\text { - } & \text { esta puesta estrategia discursiva } \\
\text { - } & \text { su impotencia } \\
\text { - } & \text { su escepticismo ante la vida } \\
\text { este fastidio por la vida }\end{array}$ & $\begin{array}{ll}\text { - } & \text { este pensamiento metropolitano } \\
\text { - } & \text { el esquema de oposiciones binarias } \\
\text { - } & \text { la originalidad } \\
\text { - } & \text { el lenguaje de los llaneros } \\
\text { - } & \text { esta riqueza } \\
\text { - } & \text { esta estructura de dominación } \\
\text { - } & \text { esta imposición } \\
\text { - } & \text { esta inveación } \\
\text { - } & \text { esta identión } \\
\text { - } & \text { su búsqueda } \\
\text { - } & \text { la transmisión narrativa } \\
& \text { ambos frentes de lucha }\end{array}$ \\
\hline
\end{tabular}

En los casos que analizamos a continuación puede observarse la reelaboración que los enunciadores realizan sobre las voces de los personajes de las diversas obras literarias que son objeto de análisis. En estas categorizaciones las EEDD cumplen la función de interpretación y posicionamiento de los TF. Así, en (12) el enunciador reformula la réplica que Miguel, personaje de la novela "En octubre no hay milagros" de Oswaldo Reynoso (2014), le hace a otro personaje (Leonardo):

(8) Leonardo, por su parte, un joven profesor amigo de Miguel, despierta de una borrachera intranquila para encontrarse al final de la narración con Miguel en la procesión del señor de los milagros e intenta hacerlo desistir de su afán de actuar diciéndole que la violencia individual no cambia nada: "[...] sólo la acción colectiva y organizada de un partido de campesinos, de obreros y gente decidida podrá cambiar todo esto que está podrido". Sin embargo, Miguel le replica del siguiente modo: "Hablas como si fueras un libro, pero mañana nos botan de casa, yo sigo 
cobarde, mi viejo se muere de tanto trabajar sin haber gozado nada, mi mamá se acaba lavando ropa cocinando renegando y a mi hermana la hacen puta y al zorro lo corrompen". Así se manifiesta su impotencia, su escepticismo ante la vida.

Podemos observar, que en las EEDD "su impotencia", y "su escepticismo ante la vida" constituyen sintagmas nominales conformados por pronombres posesivos más sustantivos o construcciones sustantivas ( $\mathrm{SN}=$ PPos.+ sust./k sust.) que poseen un valor fuertemente argumentativo y le posibilitan al enunciador interpretar y posicionarse frente a las obras literarias que analizan en sus trabajos finales. Lo mismo ocurre en (13), caso en el que el enunciador retoma la voz de uno de los personajes de la misma novela y la categoriza como "este fastidio por la vida".

(8) "Cobarde: porque corro, porque tengo miedo de cumplir veinte años, porque tengo miedo de estar solo, porque ya no creo en mi collera, porque lloré cuando me jalaron en mi examen de ingreso a San Marcos, porque ese tal Pocho me la quita a Mery y yo no le pego". Con este fastidio por la vida logra escribir algunos cuentos.

En el caso que sigue (14), "la lucha entre civilización europea y la barbarie indígena, entre la inteligencia y la materia" es etiquetada a través de un SN formado por una pronombre determinativo más un sustantivo, lo que podría enunciarse así: SN= PDet. + sust. Observamos que se construye una entidad que nueva a partir de la proposición precedente, lo implica una apropiación de la información contenida en el TF como "enfrentamientos entre posturas diferentes y antagónicas". La idea de "enfrentamientos" ostenta una cierta carga modalizadora valorativa con función argumentativa.

(9) Sarmiento en su libro Facundo (2000) expresa: "Si un destello de literatura nacional puede brillar momentáneamente en las nuevas sociedades americanas, es el que resultará de la descripción de las grandiosas escenas naturales, y sobre todo, de la lucha entre la civilización europea y la 
barbarie indígena, entre la inteligencia y la materia". Los enfrentamientos entre posturas diferentes y antagónicas [...].

La carga valorativa se hace, quizás, más evidente en los ejemplos que comentamos a continuación, en los que los ítems lexicales a partir de los cuales se condensa la información resultan en sí mismos valorativos.

(10) La reiteración periódica en relación a las posibilidades de evangelización de los pueblos encontrados es otra forma de acentuación del etnocentrismo. En referencia a esto, Cortés señala: "Yo les hice entender con las lenguas cuan engañados estaban en tener su esperanza en aquellos ídolos [...] y todos, en especial el dicho Mutezuma, me respondieron [...] que bien podrían estar errados". (2013) La imposición del cristianismo deja fuera del circuito comunicativo a los aztecas.

En (15), al retomar las declaración de Cortés y etiquetar su preoceder como "la imposición del cristianismo" se evidencia claramente la postura crítica del enunciador respecto del denominado proceso de "evangelización" de los pueblos originarios en América. Asimismo en (16):

(11) "Sarmiento en una carta personal a Mitre expresa un desprecio hacia los gauchos y su deseo de exterminarlos: 'Tengo odio a la barbarie popular. La chusma y el pueblo gaucho nos es hostil. Mientras haya un chiripá, no habrá ciudadanos"' (Fernández, 1993, p. 219). Roberto Retamar ha incluido estas palabras de Sarmiento en su escrito "Algunos usos de la civilización y la barbarie" para que no sólo quede demostrado el odio de Sarmiento hacia el gaucho y la barbarie, sino también demuestren que ese plan de exterminio era autoetnicida y absurdo, ya que eliminaba a su propio pueblo.

Aquí observamos cómo el enunciador -al interpretar las consideraciones de Fernández Retamar sobre los dichos de Sarmiento- realiza una categorización en la que se evidencia al mismo tiempo cuál es el posicionamiento del propio estudiante con respecto a la mirada de Sarmiento 
sobre el gaucho. Como vemos, el escritor retoma dialógicamente dos voces precedentes: la de Fernández Retamar, y la del propio Sarmiento. La reformulación que el estudiante realiza del antecedente: "mientras haya un chiripá, no habrá ciudadanos" como "ese plan de exterminio" hace explícitas las intenciones de Sarmiento, en tanto marca una mirada personal sobre el tema. Se trata, por lo tanto, de una modalización apreciativa a través de la cual se deja en claro la posición y la actitud del enunciador respecto de lo dicho. Lejos de adherir al ideal "civilizador" sarmientino, el enunciador interpreta y categoriza esa proposición como un "plan genocida", haciendo evidentes las intenciones de Sarmiento de exterminar al gaucho.

Los ejemplos ilustran la función metadiscursiva y modalizadora epistémica y axiológica característica de muchas etiquetas, a la vez que se aprecia su papel esencial como parte de la apropiación del discurso ajeno y la construcción ideológica en el discurso. Las EEDD son un poderoso mecanismo semantizador de carácter cognoscitivo que no solo cumple funciones referenciales y anafóricas sino también argumentativas (González, 2009), a las que los estudiantes suelen acudir con mayor o menor éxito en la reformulación e interpretación tanto de las obras literarias como de los conceptos provenientes de la bibliografía crítica.

\section{6- A modo de conclusión}

Uno de los principales desafíos con que los estudiantes se encuentran al cursar sus carreras de grado es el de poder construir conocimiento a partir del diálogo con su comunidad discursiva de pertenencia. En este trabajo, a través de un análisis cualitativo, describimos y clasificamos el despliegue de un procedimiento discursivo particular de reformulación parafrástica denominado etiquetaje discursivo. Los resultados se obtienen del análisis de un corpus de textos escritos por estudiantes avanzados de la carrera del Profesorado en Lengua y Literatura de la Universidad Nacional de Río Cuarto. En consecuencia, el alcance de esta indagación resulta limitado; no obstante, nos posibilitó advertir la relevancia de las EEDD como recurso de cohesión léxico- 
gramatical y como estrategia discursiva de reformulación parafrástica que pone en evidencia el posicionamiento y la interpretación de los enunciadores cuando se apropian de la información de TF en sus tareas de escritura.

La interpretación y el posicionamiento del enunciador hacen referencia principalmente a (1) la función metadiscursiva de algunas etiquetas, que califican el texto precedente como acto de habla, (2) la función de modalización o manifestación de la actitud del hablante frente a lo dicho, que puede indicar alguna consideración epistémica o evidencial (sobre la certeza frente a lo dicho) o alguna valoración o actitud axiológica frente a aquello que se retoma en el discurso.

Procuramos caracterizar las manifestaciones del fenómeno de etiquetaje en cuanto a los procesos de recategorización de la información que llevan a cabo, su funcionamiento metadiscursivo y la actitud del hablante o modalidad que expresan. El análisis nos posibilitó sistematizar diversos comportamientos que muestran las EEDD. Así, pudimos diferenciar tres grandes grupos según las funciones que cumplen. En primer lugar, hay EEDD que reformulan los segmentos precedentes como actos de lenguaje y cumplen funciones anafóricas de RE. En este sentido, se las puede calificar como metadiscursivas. Aunque cumplen con la función de categorizar una voz precedente, su carga valorativa es menor que las de otras formas de etiquetaje.

En segundo lugar, hay EEDD que funcionan como anáforas de dicto. Su función es interpretar el contenido proposicional del segmento precedente. En algunos casos, lo reformulan a partir de la restitución y/o desplazamiento de algún ítem lexical, y suele coincidir también con las funciones que cumplen las anáforas acumulativas. Estas últimas enfatizan la necesidad de tener en cuenta toda la cláusula en la que aparece el antecedente para interpretar la expresión anafórica. En tercer lugar, hay EEDD que funcionan como anáforas de dicto en las que el proceso de categorización construye una entidad inédita, la cual tiende a conllevar fuertes implicancias axiológicas y argumentativas.

En lo que respecta a las EEDD de dicto en general, quisiéramos destacar el efecto de modalización epistémica que genera su uso. Observamos cómo los enunciadores al retomar las 
voces precedentes y categorizarlas pone en juego la apropiación de la información para volver a nombrarla generando nuevos conocimientos. Como hemos mencionado, este tipo de reformulación parafrástica resulta altamente eficaz en la apropiación de contenidos abstractos y complejos que son propios del ámbito científico y académico. A su vez, el perfilamiento epistémico de un antecedente lo sitúa en un estatuto determinado, lo cual no sirve solo a los fines expositivos, sino también a los argumentativos, a los que también hacen su aporte, por supuesto, las etiquetas con clara modalización apreciativa.

Por último, quisiéramos destacar que los procedimientos de EEDD en tanto mecanismo anafórico de cohesión léxico-gramatical, como así también de reformulación parafrástica, pueden ser trabajados en la enseñanza de la escritura académica tanto de grado, como de posgrado. El manejo de estos recursos tiene un alto impacto no solo en términos cohesivos y de progresión de la información textual, sino también a nivel epistémico. Hacer consciente la búsqueda de un ítem léxico adecuado exige dominio acerca del tema sobre el que los estudiantes están escribiendo. Además, algunas EEDD tienen una fuerte incidencia en la orientación argumentativa que el enunciador puede imprimirle a su discurso.

\section{7- Referencias}

Abad, S. (2015). Estudio contrastivo del funcionamiento semántico de encapsuladores nominales en la prensa española y alemana. De la anáfora a la catáfora conceptual. Universidad Autónoma de Madrid. Tesis Doctoral.

Alvarado, M. y Cortés, M. (2001). La escritura en la universidad: Repetir o transformar. En: Lulú Coquette. Revista de Didáctica de la Lengua y la Literatura, 1(1).

Andújar, G. (2000). La traducción de la subjetividad del enunciador a través de ciertas marcas anafóricas. En: M. Casal Silva, G. Conde Tarrío, J. Lago Garabatos, Pino Serrano, L; Rodríguez 
Pedreira, N. (coords.). La Lingüística francesa en España camino del siglo XXI, Vol. 1, Tomo I, 91-99.

Apothéloz, D. (1995) Nominalizaciones, referencias clandestinas y anáforas atípicas. En: A. Barrendonner y M. Reichler Béguelin (eds.). Del sintagma nominal a los objetos-de-discurso. SN complejos, nominalizaciones y anáforas, 143-147.

Arnoux, E. (2009). Pasajes. Enseñanza Superior. Propuestas en torno a la lectura y la escritura. Buenos Aires: Biblos.

Arnoux, E.; Pereira, C. (2002). La lectura y la escritura en la universidad. Buenos Aires: EUDEBA.

Arnoux, E.; Silvestri, A.; Nogueira, S. (2002). La construcción de representaciones enunciativas: el reconocimiento de voces en la comprensión de textos polifónicos. Signos, 35(51-52), 129 148.

Asher, N. (1993). Reference to abstract objects in discourse, Dordrecht: Kluwer Academic Publishers. Ávila, R. (2016). Los encapsuladores nominales como técnica de escritura académica. EFDeportes.com, Revista Digital, 21(218).

Bazerman, C. (2014). El descubrimiento de la escritura académica. En: F. Navarro (ed.). Manual de escritura para las carreras de humanidades, Buenos Aires: Editorial de la Facultad de Filosofía y Letras Universidad de Buenos Aires, 11-16.

Borreguero, M. (2006). Naturaleza y función de los encapsuladores en los textos informativamente densos (la noticia periodística). Cuadernos de Filología Italiana, 13, 73-95.

Borzone, M. (2005). La resolución de las anáforas en niños: incidencia de la explecitud y la distancia. Interdisciplinaria. Revista de psicología y ciencias afines, 2(22), 155-182.

Brown, G.; Yule, G. (1983). Discourse analysis, Cambridge: Cambridge University Press.

Carlino, P. (2005). Escribir, leer y aprender en la universidad. Una introducción a la alfabetización académica. Buenos Aires: F.C.E. 
Carlino, P. (2013). Alfabetización académica diez años después. Revista Mexicana de Investigación Educativa, 18(57), 355-381.

Cornejo, A. (1999). Escribir en el aire. Ensayo sobre la heterogeneidad cultural en las literaturas andinas. Lima: Horizonte.

Cornish, F. (1990). Anáfora pragmática, referencia y modelos de discurso. En: G. Kleiber; J. Tyvaert, La anaáfora y sus denominaciones, París/Genéve: Droz.

Cortés, H. (2013). Segunda carta de relación. 30 de octubre de 1520. En: Cartas de Relación. México: Porrúa.

Feinmann, J. (1996). Filosofía y Nación. Buenos Aires: Sudamericana.

Fernández, S. (1987). El pronombre. En: Gramática Española. Madrid: Arcos.

Fernández, R. (1993). Algunos usos de la civilización y la barbarie. Buenos Aires: Buena Letra.

Fernández, A. (2009). “La expresión de la modalidad epistémica en el español científico-médico y en el español conversacional. Análisis contrastive". A survey of corpus-based research [Recurso electrónico]. Disponible en: https://www.um.es/lacell/aelinco/contenido/pdf/39.pdf

Francis, G. (1994). Labelling discourse: An aspect of nominal-group lexical cohesion. En: M. Coulthard, Advances in Written Text Analysis, Londres: Routledge, 83-101.

González, R. (2008). Las nominalizaciones como estrategia de manipulación informativa en la noticia periodística: el caso de la anáfora conceptual. En: I. Olza Moreno, M. Casado Velarde y R. González Ruiz (eds.). Actas del XXXVII Simposio Internacional de la Sociedad Española de Lingüística (SEL), Pamplona: Servicio de Publicaciones de la Universidad de Navarra.

González, R. (2009). Algunas notas en torno a un mecanismo de cohesión textual: la anáfora conceptual. En: M. Penas y R. González (eds.), Estudios sobre el texto, Frankfurt: Peter Lang, 247-278. 
González, R. (2010). Gramática y discurso: nominalización y construcción discursiva en las noticias periodísticas. En: C. Martínez Pasamar (ed.), Estrategias argumentativas en el discurso periodístico, Frankfurt: Peter Lang, 119-146.

Langacker, W. (1987). Nouns and verbs. Language, 63(1), 53-94.

Latorre, G.; Vega, O.; Opazo, C. (2002). Componentes semántico-discursivos, modalidades enunciativas y la imagen de las superpotencias en el diario ilustrado (1957-1962). ONOMAZEIN, 7, 55-70.

Llamas, C. (2010). Argumentación en la noticia periodística: El caso de la anáfora conceptual metafórica. En: C. Martínez Pasamar (ed.), Estrategias argumentativas en el discurso periodístico, Frankfurt: Peter Lang, 147-170.

López, A. (2011). La categorización de entidades en el discurso profesional. Las etiquetas discursivas como mecanismo de cohesión léxica. Barcelona: Universidad de Barcelona. Tesis Doctoral.

López, A. (2013a). Las etiquetas discursivas: del mantenimiento a la construcción del referente. ELUA. Estudios de Lingüística, 27: 167-197.

López, A. (2013b). Etiquetas discursivas, hiperónimos y encapsuladores: una propuesta de clasificación de las relaciones de cohesión referencia. Barcelona: Universidad de Barcelona.

López, A. (2018). La encapsulación nominal en el discurso académico -científico oral y escrito: patrones de aparición. Caplletra Revista Internacional de Filologia 64, 129-152.

Lyons, J. (1977). Semántica. Barcelona: Teide.

Mayela, M. ; Manrique, B. (2004). De lo fórico a lo deíctico. Un obstáculo para escribir textos plenos en Lingua Americana. Zulia: Universidad Nacional de Zulia.

Moyano, M. (2008- 2011). Apunte de cátedra. Inédito.

Navarro, F. (2017). De la alfabetización académica a la alfabetización disciplinar. En: R. Ibáñez y C. González (eds.), Alfabetización disciplinar en la formación inicial docente. Leer y escribir para aprender, Valparaíso: Ediciones Universitarias de Valparaíso, 7-15. 
Novo, M. (2007). Los géneros académicos: La reformulación. En: M. Novo y P. Rosales, La lectura y la escritura en la enseñanza de las ciencias sociales, Río Cuarto: UniRío, 155- 181.

Padilla, C. (2013). Escritura en la escuela: Prólogo. En: F. Navarro y A. Revel Chion, Escribir para aprender. Disciplinas y escrituras en la escuela secundaria, Buenos Aires: Paidós, 19-21.

Penas, M.; Serna, S. (2011). Aproximación histórica a la reformulación lingüística de la paráfrasis como caso de sinonimia sintagmática. Energeia, 3, 30-74.

Peña, G. (2006). La anáfora y su funcionamiento discursivo. Una aproximación contrastiva. Valencia: Universidad de Valencia.

Pérez, Y. (2016). La modalización discursiva en textos de José Martí para la sección Correo de los teatros, de la Revista Universal (México, 1875-1876). Entrepalavras, 6(2), 182-198.

Reynoso, O. (2014). En octubre no hay milagros. San Marcos: Lima.

Sarmiento, D. (2000) Facundo: Civilización o Barbarie. Buenos Aires: Colihue.

Scardamalia, M.; Bereiter C. (1992). Dos modelos explicativos de los procesos de producción escrita. Infancia y Aprendizaje, 58, 43-64.

Silvestri, A. (1998). En otras palabras. Las habilidades de reformulación en la producción del texto escrito. Buenos Aires: Cántaro.

Torres, C.; Boces, G. (2012) Reformulación y uso del pronombre demostrativo neutro "esto" en la elaboración de síntesis escritas por parte de estudiantes universitarios. Revista Signos, 45(79), 198-225.

Vazquez, A. (2016). La lectura, la escritura y el interés por aprender en la universidad. Problemas, saberes y propuestas, Río Cuarto: UniRío.

Vivero, M. (1997). La anáfora desde una perspectiva textual. Thélème. Revista Complutense De Estudios Franceses, (12), 533-544.

Zamponi, G. (2003). Procesos de referenciación: anáforas asociativas y nominalizantes. Campiñas: UNICAM. 